\title{
CATALYTIC ACTIVITY OF PRECIPITATED CALCIUM CARBONATE FOR BIODIESEL PRODUCTION
}

\author{
V. Sisca ${ }^{1,2}$, D.A Tanjung ${ }^{1,3}$, Syukri $^{1}$, Zilfa $^{1}$ and N. Jamarun ${ }^{1, \bowtie}$ \\ ${ }^{1}$ Department of Chemistry / University of Andalas, Padang West Sumatra 25163, (Indonesia) \\ ${ }^{2}$ Department of Biology/ STKIP YPM Bangko, Merangin Jambi 37313, (Indonesia) \\ ${ }^{3}$ Department of Agrotechnology/ University of Medan Area, Medan 2011, (Indonesia) \\ ${ }^{\square}$ Corresponding Author: novesarjamarun@sci.unand.ac.id
}

\begin{abstract}
Transesterification of used cooking oil (UCO) with methanol using calcium carbonate precipitate (PCC) as a heterogeneous catalyst was carried out under reflux with constant stirring to obtain biodiesel. Before the catalyst test, PCC was first thermally activated at $900{ }^{\circ} \mathrm{C}$ for 5 hours to obtain $\mathrm{CaO}$. and then characterized by X-Ray Diffraction (XRD), X-Ray Fluorescence (XRF) and Scanning Electron Microscopy (SEM). The effects of temperature, reaction time, methanol/oil molar ratio and amount of catalyst were investigated. The highest yield of biodiesel produced was 93\% after 4 hours reaction time using 5\%wt catalyst and methanol to oil ratio 6:1. In addition, the catalyst has good reuse potential for the synthesis of biodiesel.

Keywords: Biodiesel, Heterogeneous Base Catalysts, Used Cooking Oil, Transesterification, PCC.
\end{abstract}

RASĀYAN J. Chem., Vol. 14, No.3, 2021

\section{INTRODUCTION}

One present technological challenge is finding ways to reduce fossil fuel use while increasing energy requirements. Therefore, to replace petroleum-based fuels, clean and renewable energy needs to be developed. ${ }^{1}$ One such well-researched renewable and environmentally friendly substitute for fossil fuel is biodiesel. ${ }^{2}$ which has economic, technical, and environmental advantages. ${ }^{3}$ Previous research has shown that vegetable oil can be utilized as engine fuel if diluted, used in a microemulsion, or processed using thermal cracking (pyrolysis), or transesterification. ${ }^{4}$ Of these transesterification is most popular because of its low cost, transesterification to obtain biodiesel usually consists of a reaction between triglycerides and alcohol in the presence of a catalyst. ${ }^{5}$ The moisture content of oil or fat, free fatty acids, the molar ratio of alcohol: oil, type of catalyst, amount of catalyst, reaction temperature, and reaction time affect the transesterification reaction. ${ }^{4}$ Triglycerides from vegetable oils and short-chain alcohols are the raw material for biodiesel production. The use of virgin vegetable oil directly raises problems related to food competition. ${ }^{6}$ However, waste cooking oil can be used as an alternative.

The catalyst plays an important role in the transesterification reaction. ${ }^{7}$ A biodiesel synthesis catalyst can be homogeneous or heterogeneous. ${ }^{8}$ High biodiesel yields are obtained by using a homogeneous catalyst but the process can be expensive due to saponification, excessive use of chemicals, and additional costs for separation. ${ }^{9}$ Heterogeneous catalysts, on the other hand, have been developed that are also efficient, prevent saponification, and can be separated and reused easily. ${ }^{10} \mathrm{CaO}$ is one such catalyst. $\mathrm{CaO}$ can be obtained easily from limestone derivatives, waste eggshell, oyster and other sea shells. ${ }^{11} \mathrm{CaO}$ has high alkalinity, low solubility in methanol, and high catalytic activity. ${ }^{12}$

This research explores the use of precipitated calcium carbonate (PCC) as a heterogeneous base catalyst for biodiesel production. The precipitated calcium carbonate is sourced from limestone, which is rich in calcium carbonate $\left(\mathrm{CaCO}_{3}\right)$. A simple calcination process at high temperatures converts it into calcium oxide $(\mathrm{CaO})$, which is cost-effective and environmentally friendly. The use of precipitated calcium carbonate for the preparation of $\mathrm{CaO}$ catalysts comes from limestone obtained from the Lintau Buo area, West Sumatra. The effects of catalytic activity were investigated in the transesterification reaction of Edible Oil Waste for biodiesel production. 
RASĀYAN J. Chem.

Vol. 14 | No. 3 |1587-1593| July - September | 2021

\section{Material}

\section{EXPERIMENITAL}

Limestone was collected from Lintau Buo, West Sumatra. Used cooking oil (already used for frying three times) collected from sellers of fried food in Jati Padang, West Sumatra and its chemical composition was analyzed by GCMS. The methanol, ethanol, n-hexane used were purchased from Merck Limited, Padang, Indonesia.

\section{Catalyst Preparation}

The collected limestone was washed thoroughly to remove surface dirt using distilled water and dried at $105^{\circ} \mathrm{C}$. Then limestone was mashed and calcined in a $900{ }^{\circ} \mathrm{C}$ furnace for 5 hours. $20 \mathrm{~g}$ of the $\mathrm{CaO}$ obtained was dissolved in $300 \mathrm{ml}$ of $2 \mathrm{M} \mathrm{HNO}_{3}$, stirred for 30 minutes, then filtered. $\mathrm{NH}_{4} \mathrm{OH}$ was added to the filtrate at $60{ }^{\circ} \mathrm{C}$ until it reached $\mathrm{pH} 12$. The solution was filtered and $\mathrm{CO}_{2}$ gas was passed through it at $\mathrm{pH} 8$. The precipitate formed was filtered and washed with distilled water then dried at $100-115{ }^{\circ} \mathrm{C}$ for 2 hours ${ }^{13}$. Precipitated calcium carbonate was calcined in a $900{ }^{\circ} \mathrm{C}$ furnace for 5 hours.

\section{Catalyst Characterization}

The crystal structure of the catalyst was determined using powder X-ray diffraction (XRD) using a Pan Analytical Expert Pro X-ray diffractometer equipped with $\mathrm{Cu} \mathrm{K} \alpha$ radiation. Elemental analysis was carried out using X-ray fluorescence (XRF) using an Epsilon PANalytical Model 3. Morphological analysis of the catalyst was analyzed using Scanning electron microscopy (SEM) supplemented with X-ray spectroscopy (EDX) JEOL energy scattering, JSM-6290LV.

\section{Transesterification}

Used cooking oil was initially filtered with Whatman filter paper no. 42 to remove frying debris and heated until constant weight. The transesterification reaction was carried out in a $500 \mathrm{ml}$ triple-necked flask with a reflux condenser and a magnetic stirrer. First, the catalyst was activated with the addition of methanol and stirring. A measured amount of $100{ }^{\circ} \mathrm{C}$ used cooking oil added and the reaction carried out under the selected conditions. After the reaction was complete, the solid catalyst was filtered using a funnel with filter paper. The filtrate was transferred to a separating funnel and left to stand overnight. The lower layers were discarded, and the upper layers were collected. The resulting biodiesel was rinsed with hot distilled water until the washing water looked clear then dried at $110^{\circ} \mathrm{C}$ to remove the washing water. After that biodiesel was analyzed by gas chromatography and the yield calculated using the following formula:

$$
\text { Yield of Biodiesel }(\%)=\frac{\% \text { Area Gc BiodieselxWe of product }}{\text { weight of Used Cooking Oil }} \times 100 \%
$$

\section{Catalyst Characterization}

\section{RESULTS AND DISCUSSION}

\section{X-Ray Diffraction Analysis (XRD)}

The XRD pattern obtained from the raw and calcined PCC is presented in Fig.-1. The main characteristic peaks at $2 \theta=22.99^{\circ}, 29.34^{\circ}, 35.93^{\circ}, 39.37^{\circ}, 43.12^{\circ}, 47.46$ and $48.47^{\circ}$, corresponding to the calcium carbonate $\left(\mathrm{CaCO}_{3}\right)$ phase, are found in the crude PCC XRD pattern indicating the presence of $\mathrm{CaCO}_{3}$ in PCC. These results are also consistent with the XRF analysis presented in Table-1, showing that calcium is the main element in the PCC sample. The calcined PCC sample showed peaks corresponding to the $\mathrm{CaO}$ $(\operatorname{ICDD} 01-077-2376)$ phase $\left(2 \theta=32.19^{\circ}, 37.35^{\circ}, 53.84^{\circ}, 64.13^{\circ}, 67.36^{\circ}, 79.63^{\circ}, 88.49^{\circ}\right.$ and $\left.91,43^{\circ}\right)$ and to $\mathrm{Ca}(\mathrm{OH})_{2}(\mathrm{ICDD} 00-044-1481)\left(2 \theta=18.06^{\circ}, 28.67^{\circ}, 34.10^{\circ}, 47.14^{\circ}, 50.79^{\circ}, 54.35^{\circ}, 62.60^{\circ}\right.$ and $64.29^{\circ}$, which indicates that $\mathrm{CaCO}_{3}$ changes to $\mathrm{CaO}$ after calcination. ${ }^{14}$

The XRD results from the recycled catalyst (Fig.-1) shows a peak at $\left(2 \theta=13.64^{\circ}, 15.25^{\circ}, 20.21^{\circ}, 21.43^{\circ}\right)$ indicating that some $\mathrm{CaO}$ is changed to calcium glyceroxide, $\left.\mathrm{Ca}\left(\mathrm{C}_{3} \mathrm{H}_{7} \mathrm{O}_{3}\right)_{2}\right)$ (ICDD 00-021-1544). This new phase is formed by a reaction between $\mathrm{CaO}$ with the glycerol resulting in the transesterification reaction. ${ }^{11}$ 
RASĀYAN J. Chem.

Vol. 14 | No. 3 |1587-1593| July - September | 2021

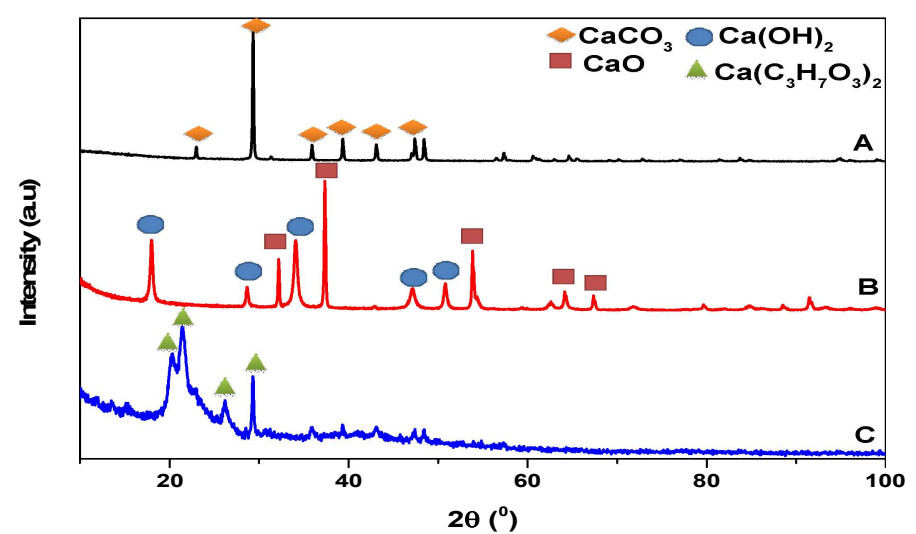

Fig.-1: X-ray Diffraction Analysis (A) PCC (B) PCC Calcined $900^{\circ} \mathrm{C}(\mathrm{C})$ after one cycle of use

\section{X-ray Fluorescence Analysis (XRF)}

Pre and post $900{ }^{\circ} \mathrm{C}$ calcination PCC composition was analyzed by XRF (Table-1). The pre calcination PCC sample was found to be $97 \%$ Ca which increased to $98 \%$ after calcination. After being used for the first transesterification process, $\mathrm{Ca}$ content decreased to $91 \%$ due to the reaction of $\mathrm{CaO}$ with glycerol forming calcium glyceroxide as previously reported. ${ }^{11}$

Table -1:X-ray Fluorescence Analysis (A) PCC (B) PCC Calcination at $900^{\circ} \mathrm{C}$ (C) after one cycle of use

\begin{tabular}{c|c|c|c}
\hline \multirow{2}{*}{ Compound } & A & B & C \\
\cline { 2 - 4 } & Conc & Conc & Conc \\
\hline $\mathrm{CaO}$ & 97.2 & 98 & 91.4 \\
\hline $\mathrm{SiO}_{2}$ & 0.2 & 0.6 & 2.3 \\
\hline $\mathrm{Al}_{2} \mathrm{O}_{3}$ & 0.6 & 0.5 & 1.4 \\
\hline $\mathrm{MgO}$ & 0.1 & 0.0 & 0.0 \\
\hline $\mathrm{Fe}_{2} \mathrm{O}_{3}$ & 0.1 & 0.0 & 0.6 \\
\hline $\mathrm{Ag}_{2} \mathrm{O}$ & 0.8 & 0.7 & 0.5 \\
\hline
\end{tabular}

\section{SEM Analysis}

The morphology of PCC that had been calcined and after the first transesterification process can be compared in Fig.-2) at the same magnification. Morphological changes on the surface of the catalyst are evident. Initially, PCC had a uniform and regular distribution of particles but after being used as a catalyst in the transesterification process larger particles are evident. This happens because intermediate products such as diglycerides, monoglycerides, glycerol or biodiesel clogged the catalyst pores causing the loss of active sites and reducing subsequent catalytic activity. ${ }^{15}$

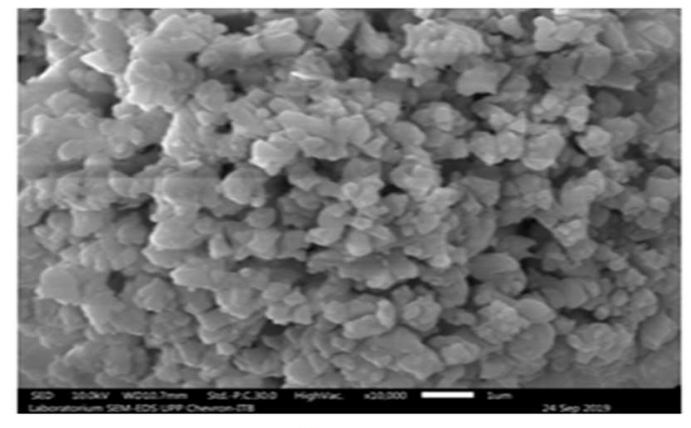

A

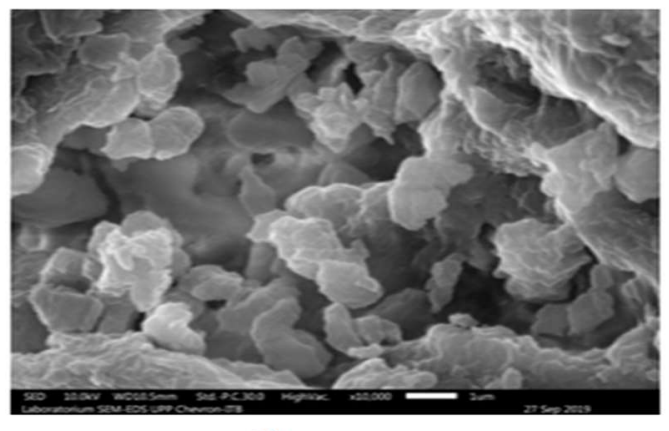

B

Fig.-2:SEM of PCC (A) Before use as a Transesterification Catalyst (B) After one cycle of use

\section{Catalytic Activity in Transesterification}

The catalytic activity of calcined PCC was evaluated for the following reaction parameters: the amount of catalyst, the molar ratio of methanol to oil, reaction time and temperature. 


\section{Amount of Catalyst}

The effect of the amount of catalyst $(1,3,5$ or $7 \mathrm{wt} \%)$ was investigated on reactions at $65{ }^{\circ} \mathrm{C}$ for $4 \mathrm{~h}$ using a 6: 1 methanol: oil ratio. Results are shown in (Fig.-3). Calcium oxide plays an important role in making methanol a more reactive nucleophile (anion methoxide) species that will attack the carbonyl groups in triglycerides. ${ }^{16}$ It was found that up to $5 \mathrm{wt} \%$ the more $\mathrm{CaO}$ catalyst added the higher the yield of biodiesel. Increasing $\mathrm{CaO}$ after this optimum value had been reached resulted in reduced yields due to secondary reactions of the catalyst with reactants. ${ }^{17}$

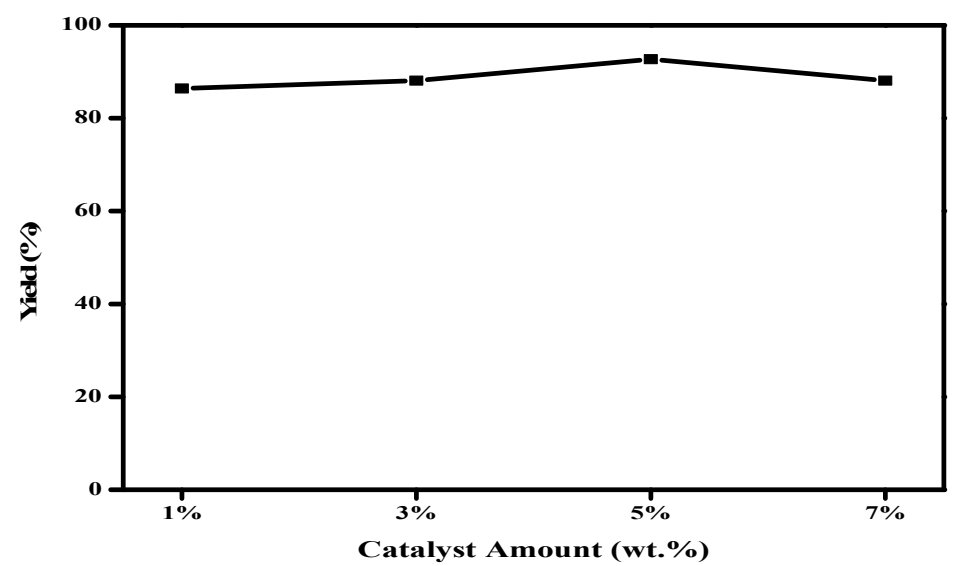

\section{Ratio of Methanol to Oil}

Fig.-3:Effect of Catalyst Amount on Yield

The ratio of methanol to oil significantly affected the yield. Experiments to test the ratios 3:1, 6:1, 9: 1 and 12: 1 of methanol to oil were carried out at $65^{\circ} \mathrm{C}$ for $4 \mathrm{~h}$ using $5 \mathrm{wt} \%$ catalyst. Figure- 4 shows that the yield of biodiesel increases with increasing ratio of methanol to oil up until an optimal value at 6: 1. Higher concentrations of methanol accelerate the formation of methoxide species on the catalyst surface so shifting the equilibrium towards the formation of methyl esters. ${ }^{18}$ However, biodiesel yields begin to decrease when the ratio of methanol to oil exceeds 6:1. Transesterification is a reversible reaction and the solubility of the by-product glycerol increases with excess methanol. ${ }^{19}$

\section{Reaction Time}

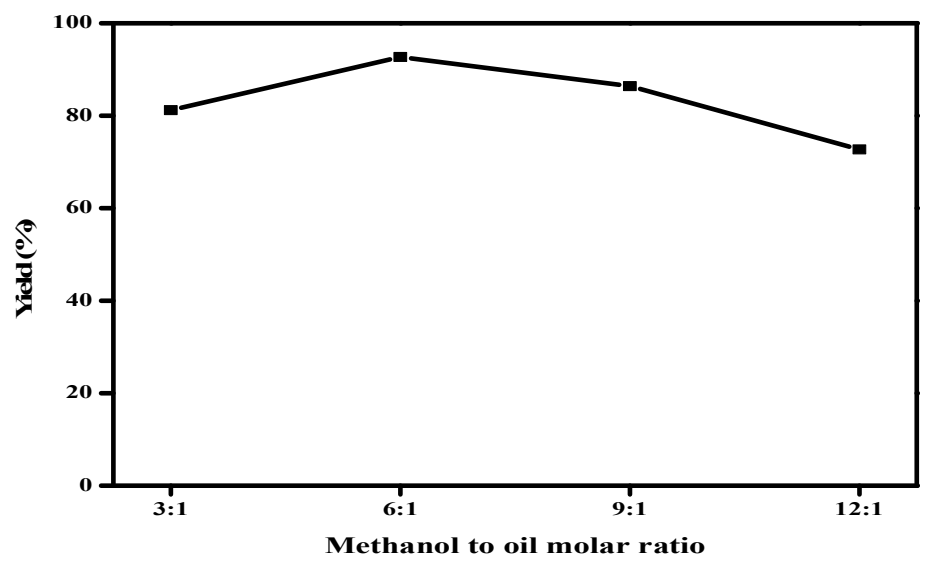

Fig.-4:Effect of Methanol Oil Molar Ratio on yield

The effect of 2, 4, 6 and $8 \mathrm{~h}$ reaction times on the yield of biodiesel production is shown in (Fig.-5). These reactions were at $65^{\circ} \mathrm{C}$ and used $5 \mathrm{wt} \%$ of catalyst and a methanol: oil ratio 6: 1 . The optimal reaction time was found to be about 4 hours. The yield of biodiesel was low for short reaction times because the use of heterogeneous catalysts does not result in a fast reaction. ${ }^{20}$ Yield increased up to a reaction time of 4 hours. After that, a white gel began to form due to saponification which affected the purification process and increased the viscosity of the product. ${ }^{21}$ 
RASĀYAN J. Chem.

Vol. 14 | No. 3 |1587-1593| July - September | 2021

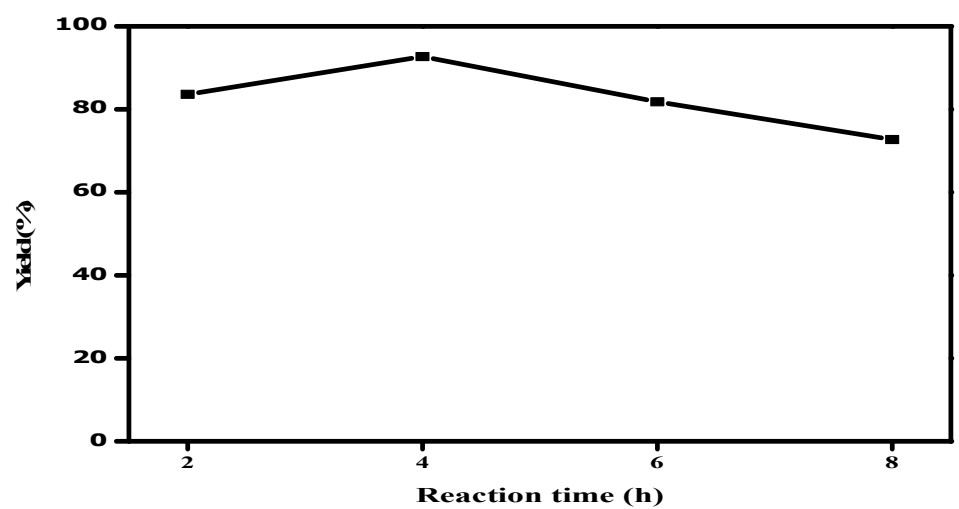

\section{Effect of Temperature}

Fig.-5:Effect of Reaction Time on yield

The effect of $55,60,65$ and $70^{\circ} \mathrm{C}$ reaction temperatures on yield was investigated using reaction $5 \mathrm{wt} \%$ catalyst, methanol: oil ratio 6: 1 and $4 \mathrm{~h}$ reaction durations as shown in (Fig.-6). It was observed that temperature had a positive effect on methanolysis from used cooking oil. The yield of biodiesel increased significantly as the reaction temperature increased up to $65^{\circ} \mathrm{C}$. However, a reaction temperature exceeding this optimal value reduced biodiesel yield. In general, an increase in temperature increases kinetic energy which results in more and harder collisions between reactant molecules. ${ }^{22}$ This can increase miscibility and mass transfer between reactants. However, exceeding the optimum conditions causes methanol to evaporate and reduces its concentration. ${ }^{23}$

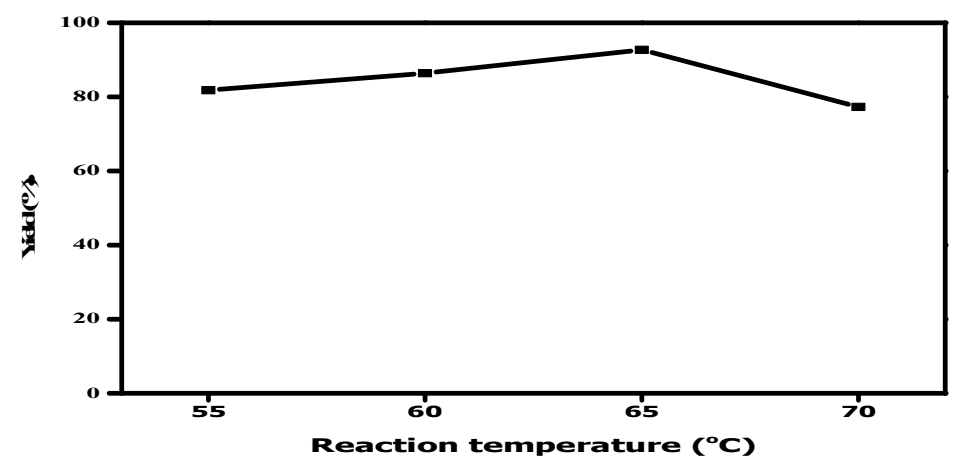

\section{Reusability}

Fig.-6:Effect of Reaction Temperature on Yield

Heterogeneous catalysts can be recovered and reused to reduce production costs. ${ }^{24}$ To test reusability reactions were conducted under optimal reaction conditions. Fresh reactants were used then, after the reaction, collected using filter paper and washed using n-hexane and methanol to remove impurities. ${ }^{21}$ It can be seen from (Fig.-7) that the biodiesel yield decreased from $92.7 \%$ to $59.1 \%$ when the same catalyst was reused over four reaction cycles.

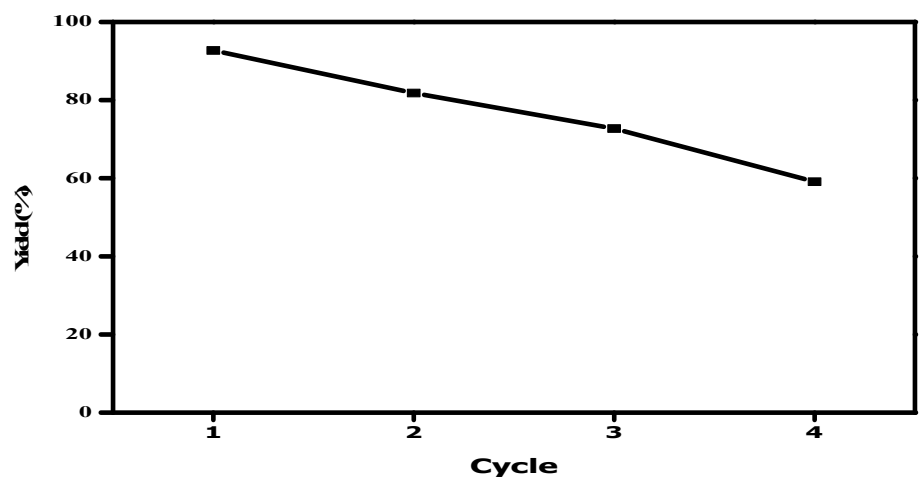

Fig.-7:Reusability Test results 
RASĀYAN J. Chem.

Vol. 14 | No. 3 |1587-1593| July - September | 2021

This reduced biodiesel yield is due to reduced catalytic activity as some of the calcium oxides are lost in the washing of active species. ${ }^{10}$ Also, some catalyst deactivation occurs as catalyst pores are blocked by intermediate products including diglycerides, monoglycerides, glycerol and biodiesel reducing contact between the catalyst and the reactant mixture. ${ }^{17}$

\section{CONCLUSION}

PCC from limestone is the source of an effective $\mathrm{CaO}$ heterogeneous catalyst for the transesterification of waste cooking oil after $900{ }^{\circ} \mathrm{C}$ calcination for 5 hours. The reaction time, reaction temperature, and ratio of methanol to oil are the parameters investigated. The maximum yield $(92.7 \%)$ of biodiesel was obtained at $65^{\circ} \mathrm{C}$ using $5 \%$ by weight catalyst, methanol to oil ratio of $6: 1$ and reaction time of 4 hours. Viable amounts of catalyst remained for three cycles of reaction.

\section{ACKNOWLEDGEMENT}

The authors thank Andalas University, the Ministry of Research, Republic of Indonesia, because the DP2M DIKTI supported part of this work in the 2018 Post-Graduate Research Grant By LPPM Andalas University, Research Grant No. 02/UN.16.17/PP.PTP/LPPM/2018.

\section{REFERENCES}

1. R.Olivia, N. Jamarun, S. Arif, Y.A Sirin, Rasayan Journal of Chemistry, 10(1), 160(2017), https://doi.org/10.7324/RJC.2017.1011555

2. K. N. Krishnamurthy, S. N. Sridhara, and C. S. Ananda Kumar, Renewable Energy, 146, 280(2020), https://doi.org/10.1016/j.renene.2019.06.161

3. Z. B. Todorović, Dragan Z. Troter, Dušica R. Đokić-Stojanović, Ana V. Veličković, Jelena M. Avramović, Olivera S. Stamenković, Ljiljana M. Veselinović, Vlada B. Veljković, Fuel, 237, 903(2019), https://doi.org/10.1016/j.fuel.2018.10.056

4. F. W. Trisunaryanti, Triyono, C. Paramesti, S. Larasati, N. R. Santoso, and D. A. Fatmawati, Rasayan Journal of Chemistry, 13(3), 1386(2020), http://dx.doi.org/10.31788/RJC.2020.1335840

5. M. Farooq, A. Ramli, A. Naeem, S. ahmad, M. Ghayas U1 Islam, Chemical Engineering Research Design, 132, 644(2018), https://doi.org/10.1016/j.cherd.2018.02.002

6. L. Da Silva Castro, A. G. Barañano, C. J. G. Pinheiro, L. Menini, and P. F. Pinheiro, Green Processing and Synthesis, 8 , 235(2019), https://doi.org/10.1515/gps-2018-0076

7. E. E. Çakırca, G. N Tekin, O. İlgen, and A. N Akın, Energy and Environmental, 30, 176(2019), https://doi.org/10.1177/0958305X18787317

8. Z. U. Zango, H. A. Kadir, S. S. Imam, A. I. Muhammad, and I. G. Abu, American Journal of Chemistry, 9(2), 27(2019), https://doi.org/10.5923/j.chemistry.20190902.01

9. F. Yaşar, Fuel, 255, 115828 (2019), https://doi.org/10.1016/j.fuel.2019.115828

10. T. Maneerung, S. Kawi, Y. Dai, and C. H. Wang, Energy Conversion and Management, 123, 487(2016), https://doi.org/10.1016/j.enconman.2016.06.071

11. S. Sirisomboonchai, M. Abuduwayiti, G. Guan, C. Samart, S. Abliz, X. Hao, K. Kusakabe, A. Abudul, Energy Conversion and Management, 95, 242(2015), https://doi.org/10.1016/j.enconman.2015.02.044

12. J. Nair, Y.V.V.S. Murthy, M. Ramesh and G. Edeira, Rasayan Journal of Chemistry, 12(4), 1757(2019), http://dx.doi.org/10.31788/RJC.2019.1245273

13. N. Jamarun, S. Yuwan, R. Juwita, J.Rahayuningsih, Journal of Applicable Chemistry, 4, 542(2015).

14. W. Suryaputra, I. Winata, N. Indraswati, and S. Ismadji, Renewable Energy, 50, 795(2013), https://doi.org/10.1016/j.renene.2012.08.060

15. T. Maneerung, S. Kawi, and C. H. Wang, Energy Conversion and Management, 92, 234(2015), https://doi.org/10.1016/j.enconman.2014.12.057

16. J. Gupta and M. Agarwal, AIP Conference Proceedings International Conference on Emerging Technologies: Micro to Nano, 1724, 0200661(2016), https://doi.org/10.1063/1.4945186

17. S. L. Lee, Y. C. Wong, Y. P. Tan, and S. Y. Yew, Energy Conversion and Management, 93, 282(2015), https://doi.org/10.1016/j.enconman.2014.12.067

18. L. J. Konwar, J. Boro, and D. Deka, Energy Sources, Part A: Recovery Utilization and Environmental Effects, 40, 601(2018), https://doi.org/10.1080/15567036.2012.733483 
RASĀYAN J. Chem.

Vol. 14 | No. 3 |1587-1593| July - September | 2021

19. A. N. R. Reddy, A. A. Saleh, M. S. Islam, and S. Hamdan, Journal of Chemistry, 1, 1(2017), https://doi.org/10.1155/2017/1489218

20. A. Birla, B. Singh, S. N. Upadhyay, and Y. C. Sharma, Bioresource Technology, 106, 95(2012), https://doi.org/10.1016/j.biortech.2011.11.065

21. J. Gimbun, S. Ali, C. C. Kanwal, L. Amer Shah, N. Muhamad Ghazali, C. Kui Cheng, S. Nurdin, Advances in Materials Physic and Chemistry, 2, 138(2012), https://doi.org/10.4236/ampc.2012.24B036

22. S. Gopal and C. Sajitha, International Journal of Scientific and Research Publications, 3, 1(2013), https://doi.org/10.29322/ijsrp

23. H. Zhu, WU Zongbin, C.Yuanxiong, Z. Ping, D. Shijie, L. Xiaohua, M. Zongqiang, Chinese Journal of Catalysis, 27, 391(2006), https://doi.org/10.1016/S1872-2067(06)60024-7

24. Y. B. Jo, S. H. Park, J. K. Jeon, C. H. Ko, C. Ryu, and Y. K. Park, Applied Biochemistry and Biotechnology, 170, 1426(2013), https://doi.org/10.1007/s12010-013-0279-y

[RJC-6167/2020] 